\title{
Influence of Current Intensity and Shielding Gas in GMAW of DH36 Grade High Strength Steel
}

\author{
M. EKICI ${ }^{a, *}$, U. ÖZSARAC̨C ${ }^{b}$ AND S. ASLANLAR ${ }^{b}$ \\ ${ }^{a}$ Yalova University, Vocational School of Yalova, Yalova, Turkey \\ ${ }^{b}$ Department of Metallurgical and Materials Engineering, Faculty of Technology, Sakarya University, Sakarya, Turkey
}

In this study, DH36 high strength steel plates having $12 \mathrm{~mm}$ thickness were joined by welding wire (EN 758 : T46 4 M M 1 H5) in gas metal arc welding technique. Shielding gas compositions were selected as $100 \%$ argon and $20 \%$ $\mathrm{CO}_{2}+80 \%$ argon gas mixture in order to investigate the effect of $\mathrm{CO}_{2}$ on mechanical properties. The welded joints were prepared at $170 \mathrm{~A}, 24 \mathrm{~V} ; 190 \mathrm{~A}, 27 \mathrm{~V}$, and $210 \mathrm{~A}, 30 \mathrm{~V}$ welding parameters. Tensile strength, the Charpy impact tests, microstructure of welded materials and their microhardness distribution throughout joining were determined. Micro and macrostructure photos and scanning electron microscopy micrographs of specimens were obtained. This study investigated the effects of current intensity on microstructure and microhardness distribution of transition zone between DH36 high strength hull steel and gas metal arc welding joint. The optimum parameters were advised to users at the end of this study.

DOI: 10.12693/APhysPolA.134.362

PACS/topics: shielding gas, current intensity, gas metal arc welding, DH36 grade steel, tensile strength

\section{Introduction}

Many industries, especially transportation (railways, automotive, shipbuilding, and aerospace), are considered to be major investors in advanced welding research because of the direct impact of the research outcomes on their product quality and versatility. In recent years, this investment has promoted the development of more advanced welding techniques than the commonly used arc welding processes. The prerequisites necessary for commercializing these continually developing techniques are: moderate infrastructure investment, minimum edge preparation, high productivity, wide chemical composition tolerance, defect free welding, low heat input, and minimum distortion. In some cases, where good weld quality and very small heat affected zone (HAZ) damage are of supreme importance the laser welding process is often considered $[1,2]$ despite the disadvantage of requiring high infrastructure investment. Shielding gases are fundamental to the operation of the gas metal arc welding (GMAW) process and there are a number commonly used, each with their own specific properties, i.e. ionization potential, which creates unique arc characteristics [3-8]. Shielding gases are also commonly used in a variety of premixed combinations of two or more gases in order to take advantage of the beneficial properties of each gas $[9,10]$. Recently however, there has been some positive research $[2,4]$ into the effects of alternating shielding gases in both GMAW and, to a lesser extent, in gas tungsten arc welding. For example, Kang et al. [5] reported that the use of alternating shielding gases can reduce the overall weld cost by approximately $17 \%$ whilst

*corresponding author; e-mail: mekici@yalova.edu.tr also considerably reducing distortion. Chang [3] reported that the use of alternating shielding gases created beneficial effects on the weld pool and different flow vectors were created in the weld pool for different gases used. However, when alternating between shielding gases, complex flow patterns were created which caused a dynamic action in the weld pool and this is known to be a result of the fluctuation between these individual shielding gas flow vectors. The dynamic nature of the shielding gas delivery is known to be influenced by factors such as arc pressure variation, variation in weld pool fluidity, and arc pressure peaking.

In present study, DH36 grade high strength steels were tried to join by GMAW by using different current intensities, and shielding gas rate, and then the tensile and impact toughness properties of butt welded specimens were measured by destructive tests.

\section{Materials and equipment}

The material used throughout the experiments was $12 \mathrm{~mm}$ thick DH36 grade steel in the form of $300 \mathrm{~mm}$ wide bar with a typical chemical composition shown in Table I. The average welding parameters are shown in Table II. The gas flow was controlled using an electronic control unit, which allowed the alternating frequency to be accurately set prior to welding whilst implementing an oscilloscope for validation. There are various filler materials used in industry depending upon the application and the ability of each to be used in a particular weld position including solid wire, metal cored wire and flux cored wire. $1.4 \mathrm{~mm}$ metal cored wire (EN 758: T46 4 M M 1 H5), which has a typical all weld metal chemical composition shown in Table I, was used throughout experimentation with a constant feed speed of $90 \mathrm{~mm} / \mathrm{s}$. 
Chemical composition and mechanical properties of DH36 steel and filler wire (wt\%)

TABLE I

\begin{tabular}{c|c|c|c|c|c|c|c|c}
\hline \hline Elements & C & Mn & Si & P & Cr & $\mathrm{Ni}$ & $\mathrm{Al}$ & $\mathrm{Cu}$ \\
\hline DH36 & 0.16 & 1.45 & 0.18 & 0.02 & 0.26 & 0.03 & 0.04 & 0.03 \\
EN 758: T46 4 M M 1 H5 & 0.05 & 1.20 & 0.50 & 0.01 & - & - & - & - \\
\hline
\end{tabular}

\begin{tabular}{|c|c|c|}
\hline Mechanical properties & DH36 & EN 758: T46 4 M M 1 H5 \\
\hline yield stress [MPa] & 425 & 460 \\
\hline ultimate strength $[\mathrm{MPa}]$ & 592 & 635 \\
\hline elongation [\%] & 21 & 22 \\
\hline absorbed energy $[\mathrm{J}]-30^{\circ} \mathrm{C}$ & 63 & 64 \\
\hline
\end{tabular}

Typical welding parameters

TABLE II

\begin{tabular}{c|c|c|c|c}
\hline $\begin{array}{c}\text { Shielding } \\
\text { gas }\end{array}$ & $\begin{array}{c}\text { Gas flow } \\
\text { rate [l/min] }\end{array}$ & Voltage [V] & Current [A] & $\begin{array}{c}\text { Welding } \\
\text { speed [mm/s] }\end{array}$ \\
\hline $100 \% \mathrm{Ar}$ & $15 \mathrm{l} / \mathrm{min}$ & $24,27,30$ & $170,190,210$ & $2,2.5,3$ \\
\hline $80 \% \mathrm{Ar}$ & $15 \mathrm{l} / \mathrm{min}$ & $24,27,30$ & $170,190,210$ & $2,2.5,3$ \\
$20 \% \mathrm{CO}_{2}$ & & &
\end{tabular}

\section{Results and discussion}

Tensile testing were undertaken to evaluate the yield stress and tensile stress of the welds examined during this investigation. The tests were performed in accordance with ISO standards using an Instron $8802250 \mathrm{kN}$ servo-hydraulic uniaxial testing machine. All tensile samples fractured in the parent material, exhibited an average yield stress of $443 \mathrm{MPa}$. The obtained results were shown in Fig. 1.

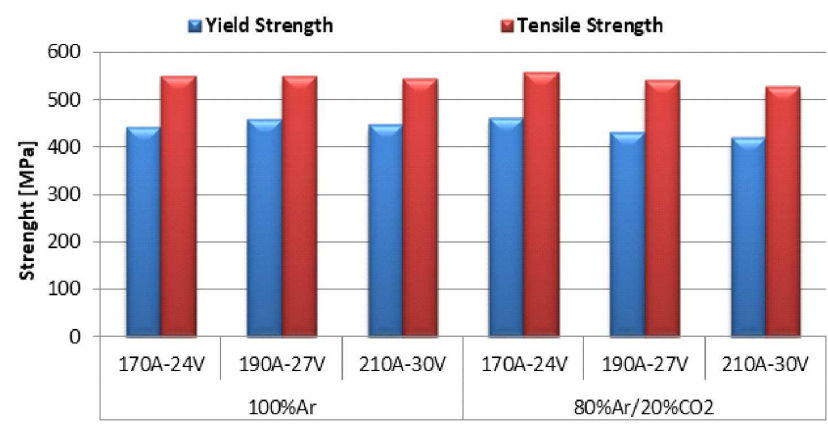

Fig. 1. Tensile test results of all specimens.

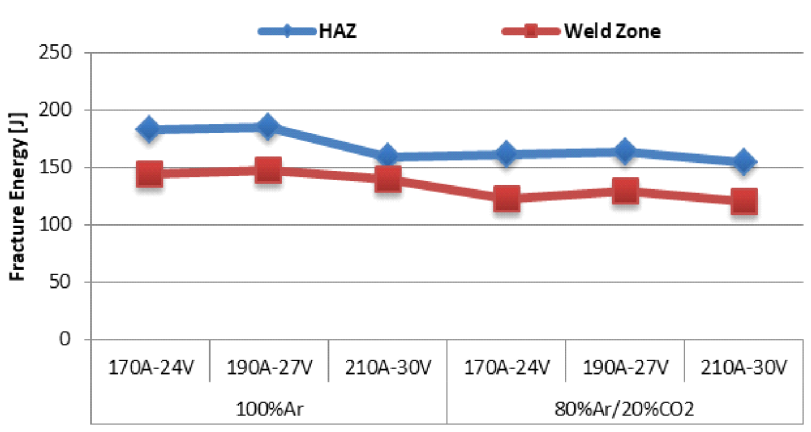

Fig. 2. Charpy impact test results of all specimens.
In Fig. 2, the fracture energies of HAZ and joint zone of weldments in room temperature were seen. The highest energy value was obtained in $190 \mathrm{~A}$ weld current and $27 \mathrm{~V}$ arc voltage in both samples used $100 \% \mathrm{Ar}$ and $80 \% \mathrm{Ar}$ $+20 \% \mathrm{CO}_{2}$ as shielding gas.

The DH 36 steel was welded by rutil electrode in butt joint position by GMAW method and the microstructure measurements were done with $0.5 \mathrm{~mm}$ spacings from base metal to HAZ through weld zone. The results were given in Fig. 3. The microhardness was increased from base metal to joint zone in all samples. The mean value of it for base metal and heat affected zone (HAZ) was measured as $165 \mathrm{HV}_{0.2}$ and $182 \mathrm{HV}_{0.2}$, respectively. In addition, the highest hardness was gained in the sample joined by $210 \mathrm{~A}$ weld current and $30 \mathrm{~V}$ arc voltage.
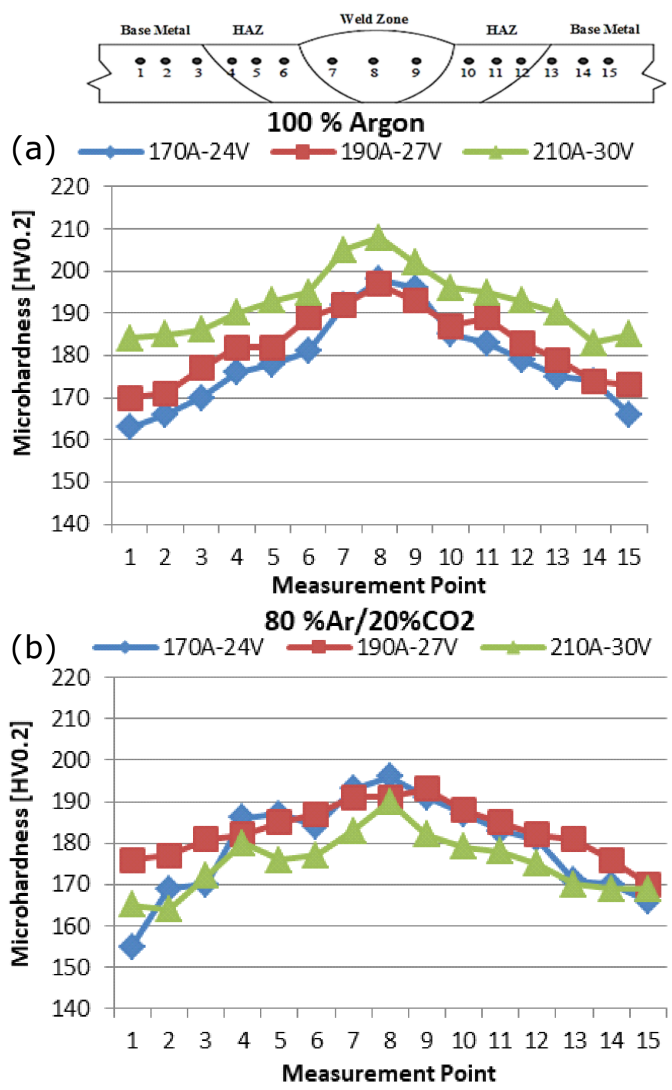

Fig. 3. Results of microhardness of all specimens: (a) $100 \%$ argon, (b) $80 \% \mathrm{Ar} / 20 \% \mathrm{CO}_{2}$. 

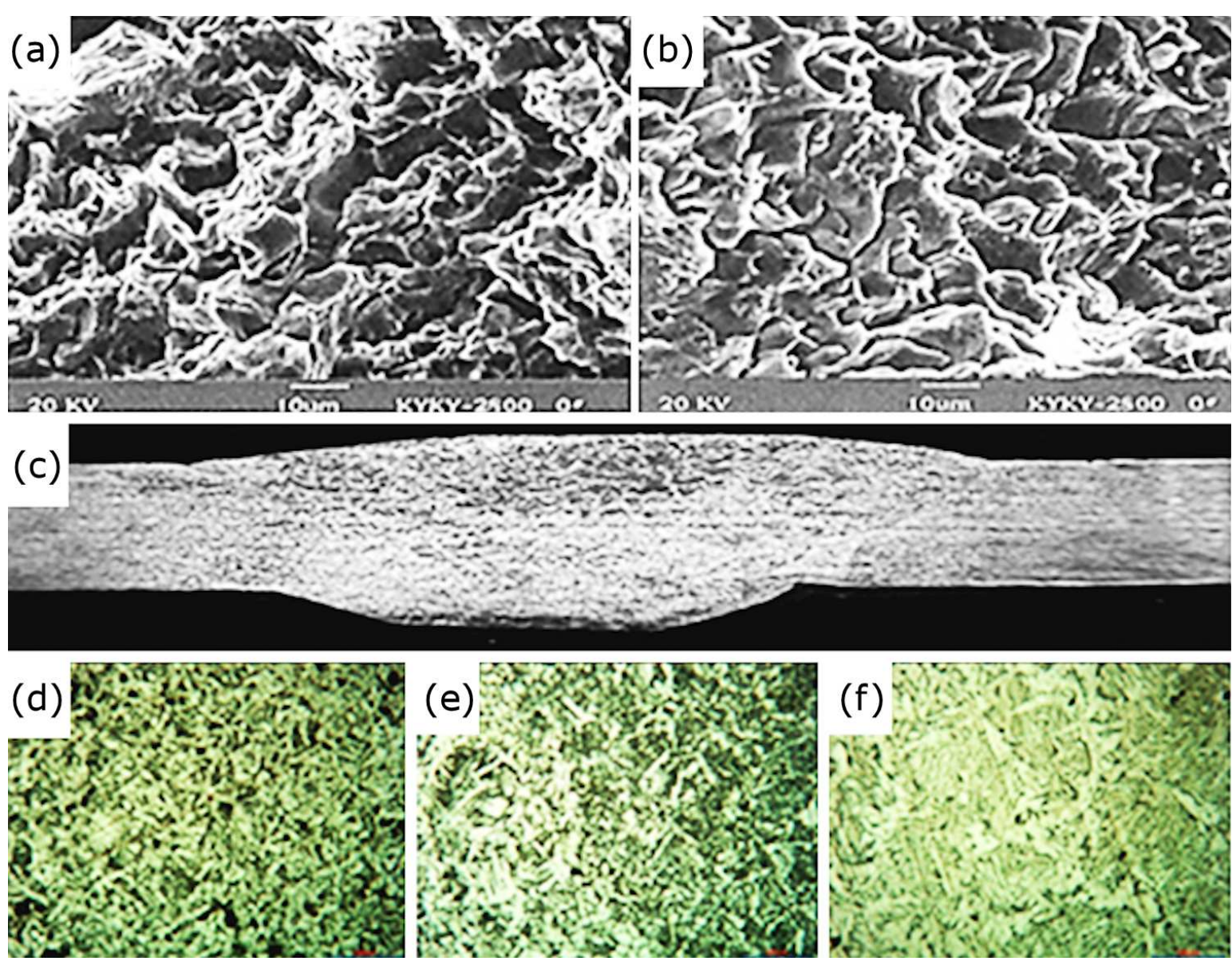

Fig. 4. Optical micrographs of DH36 steels: (a,b) SEM micrograph, (c) macro structures, (d) base metal, (e) HAZ zone, (f) weld zone.

The microstructure of ferritic/pearlitic DH36 steel joined by GMAW method with different welding parameters was seen in Fig. 4. The fracture surfaces after tensile test were given in Fig. 4a,b. The intragranular type fracture with a ductile manner was observed. The macrostructure of butt joint specimen welded by $190 \mathrm{~A}$ weld current and $27 \mathrm{~V}$ arc voltage by $100 \% \mathrm{Ar}$ shielding gas was seen in Fig. 4c. The weld bead, height and penetration depth were increased by increasing weld current and their mean values were measured as 6.83, 2.53 , and $2.3 \mathrm{~mm}$, respectively. The results are similar with the studies of Kang et al. [4], Tani et al. [7], and Galloway et al. [8].

\section{Conclusion}

In general, the better results were obtained in specimens welded by $100 \%$ Ar shielding gas in GMAW method with respect to mechanical and microstructure properties. The optimum welding parameters were seen as $190 \mathrm{~A}$ weld current and $27 \mathrm{~V}$ arc voltage for both $100 \% \mathrm{Ar}$ and $80 \% \mathrm{Ar}+20 \% \mathrm{CO}_{2}$ shielding gas compositions. After the tensile test, it was seen that the fracture occurred in base metal and an average tensile strength as $547 \mathrm{MPa}$ was gained. The microstructure results showed the increase from base metal, HAZ, and weld zone. The frac- ture energies calculated in HAZ were higher than that of weld zone. The mean value of it was $160 \mathrm{~J}$ for $100 \% \mathrm{Ar}$ shielding gas samples and $141 \mathrm{~J}$ for $80 \% \mathrm{Ar}+20 \% \mathrm{CO}_{2}$.

\section{References}

[1] N.A. McPherson, Weld. Cutt. 5, 277 (2006).

[2] F. Roland, L. Manzon, P. Kujala, M. Brede,. J. Weitzenböck, J. Ship Product. 20, 200 (2004).

[3] Y.H. Chang, Weld. J. 85, 41 (2006).

[4] B.Y. Kang, K.D.V. Prasad Yarlagadda, M.J. Kang, H.J. Kim, I.S. Kim, J. Mater. Process. Technol. 209, $4722(2009)$

[5] B.Y. Kang, K.D.V. Prasad Yarlagadda, M.J. Kang, H.J. Kim, I.S. Kim, J. Mater. Process. Technol. 209, 4716 (2009).

[6] M. Ekici, U. Özsarac,, Acta Phys. Pol. A 123, 289 (2013).

[7] G. Tani, A. Ascari, G. Campana, A. Fortunato, Appl. Surf. Sci. 254, 904 (2007).

[8] A.M. Galloway, N.A. McPherson, T.N. Baker, J. Mater. Des. Appl. 225, 61 (2011).

[9] M. Ekici, U. Özsaraç, Acta Phys. Pol. A 125, 529 (2014).

[10] N. McPherson, Weld. J. 89, 30 (2010). 